\title{
DEPRESSION IN WORKING AND NON-WORKING WOMEN IN PAKISTAN: A COMPARATIVE STUDY
}

\author{
Fareda Zeab ${ }^{*}$ \\ Uzma Ali ${ }^{* *}$
}

\begin{abstract}
The purpose of this study was to explore the difference of depression between working and non-working women of Pakistan. The sample comprised of 250 (125 working, 125 non-working) women. The target group's age range was between 28 to 45 years. The women were selected from different organizations and areas of Karachi, Pakistan through purposive sampling technique. After taking the permission from authorities and informed consent from the participant demographic forms were filled then in order to measure the depression, Lovibond and Lovibond DASS Scale (1995) was administered, individually. Descriptive statistics and t-test for independent mean were used to analyze the data through Statistical Package Social Science Version 12(SPSS V 12). It was hypothesized that "the working-women will score lower on the variable of Depression as compared to non-working women. The findings show that non-working women scored higher on the scale of depression than working-women in Pakistan. The Mean score of the age was $(M=34.126)$ and the standard deviation was $(S D=4.129)$. The Mean score of Depression of Non-working women was 14.28 and the Mean score of Depression of working women was10.26. The scores depict the lower level of depression in working women compared to non-working women.
\end{abstract}

Keywords: Depression, working women, non-working women, mental health, Pakistan, education

\section{Introduction}

According to Livinbond and Livinbond, "Depression is characterized by self-disparaging, dispirited, gloomy, blue, convinced the life has no meaning or value, pessimistic about the future, unable to experience enjoyment or satisfaction, unable to become interested or involved, show lacking in initiative". 1

Munchinsky narrated that healthy people are not necessarily those, who are not suffering by any illness or disability, but they should feel well physically, mentally and socially. ${ }^{2}$

\footnotetext{
*Fareda Zeab, Ph.D. Assistant Professor, Nazeer Hussain University, Karachi

** Uzma Ali, Ph.D. Professor, Director, Institute of Clinical psychology, University of Karachi

${ }^{1}$ S.H. Lovibond and P.F. Lovibond, Manual for the Depression Anxiety Stress Scales: (Sydney, Psychology Foundation, 2005): 212

${ }^{2}$ Munchinsky, Employee Absenteeism: A Review of the Literature. Journal of Vocational Behavior, 10, (2007): 336
} 
According to many cognitive behavioral theorists including Aaron, T. Beck et al., defined depression as a result of distorted thought and maladjustment in the society or to a social group caused by irrational way of thinking, false beliefs and maladaptive behavior. ${ }^{3}$

Depressive feeling can be socially learned from one another leading to a lack of experience and affected coping skills. According to Cognitive Depression Paradigm, depressed people's thinking pattern is different from normal people. Sufferers think negatively and passively, they feel hopelessness and take a stressor or problem worse than it actually is. Beck added that a person having negative thinking and false beliefs is susceptible to not only emotional but to physical illness.

A large sector of employed ladies in Karachi, are the refugees of Northern areas of Pakistan. Their families (male counterpart e.g. father, husband \& brother) live in the villages. In spite, women of such families work in the city areas, having great addition of their family budget, these women are bound to follow the old traditions. It was observed by the registered marital court cases that due to traditional styles of brought up, women are forced to submit to the male domination, further $\mathrm{Zeab}^{4}$ added in the study that women are not allowed to select their life partner, even; they are not told that to whom, she would be marrying. Beck revealed that Depression, Anxiety, Stress and other mental disorders are interlinked with each other. A woman, feeling of rejection or failure gets her perception distorted. She takes the matters passively with no hope. The hopelessness leads to helplessness, isolation and lack of motivation. Such conditions promote to a women to think as the future is dark, nothing may be improved. In spite having education and skills, females shake their confidence and decision making powers because of undue family and social restrictions.

Freud explained that ${ }^{5}$ the childhood exposures establish one's personality. The five stages were identified between the first five years of life. Freud further told that personality is consists of three main factors; Id is an innate instinct, it works on pleasure principle. It is associated with erose; a type of innate energy that works for pleasing oneself, to live by. Ego creates a motivational energy; to gratify the Id's needs of pleasure and to satisfy the Super ego. It also uses defense mechanism to prevent the self from the super ego's threats. According to Freud, the stronger the ego, one has, the greater the personality, one should has. The internal psychological system starts working from the childhood. The system is governed by super ego, the conscious and the unconscious. The super ego works on morality principle; according to the social norm and culture to which the person belongs e.g. Western or Asian. Super ego, either, praises the ego, if it works according to the norms at per need of the Id, or threats, just in case against the culture and the morality. As a result of praise, the personality grows well having the higher self-esteem and lesser chances of mental illness e.g. depression, anxiety and stress.

\footnotetext{
${ }^{3}$ Aaron T. Beck, A. John Rush, Brian F. Shaw and Gary Emery, Cognitive Therapy of Depression: (New York: The Guilford Press, 1979) 11.

${ }^{4}$ Fareda Zeab, Feeling of security-insecurity in working-women \& non-working-women in Pakistan, Post Graduate Unpublished thesis: (UK: Bucks New University, 2011):30

${ }^{5}$ Sigmund Freud, Analysis of phobia of a five year old boy: (The Pelican Freud Library 1977), Case Histories 8, no. 1,222
} 
Psychodynamic theory of learning asserts that one's behavior is the reflection of the unconscious and conscious. The human unconsciously adapts the culture, the religion and social rituals from the childhood. The latest medical and psychological researches revealed that the human's unconscious starts to develop in the mothers' womb. The fetus starts perceiving mothers emotions from the twelfth week of the gestational age, and starts responding from the twentieth week.

In view of the learning paradigm, it may be concluded that the Pakistani woman learns the feeling of insecurity, lower self-esteem and depressive characteristics by birth e.g. being unwanted, helplessness and gender discriminations. Since, people in Pakistan feel emotionally upset, on the birth of a daughter. Generally, Pakistan's patriarchal society brought the children with gender discriminations. The parents wish to have born male boy and give priority to the sons. The girls feel in different in the set up that leads psychological pain causing anxiety and depression coupled with feeling of insecurity.

In order to overcome the deficit of the love and respect that is the basic need of mankind, a woman likes to work. She gratifies the need of to be loved and respect. Workingwomen gain the self-esteem because ego gets the praise of super ego by doing morally well. As a result, working-women may have the better mental health than the housewives.

Psychodynamic social theory is based on to the social factors, suggesting that the personality made up by the environment and social interactions. The human behaviour reacts in a predictable manner by learning the external factors, e.g. usually a male child behave like his father, adapt the same profession as the father and the elders of the family.

However, Albert Bandura stressed ${ }^{6}$ the social interaction is the main element of the personality make up. The idea does not agree with the aspect that a child learns helplessness by imitation. Albert Bandura describes the personality as a result of learnt warmth, love and respect towards a child. Reinforcement and reward are the substantial tools to shape up the child personality. There are two defined aspects of social learning theory; those are created by Albert Bandura to explain the personality development.

The phenomenon of learning is characterized by the way of people behavior towards a person and the persons own image for him. This is the matter of alignment of thinking patterns. A person feel happy and respected, if the other people behave nicely and politely. The person learning ability and motivational energy may be improved through unconditional positive regards. One gains the self-esteem and minimizes the suffering in mental disorders. Nevertheless, gender prejudices, undue boundaries to have education for women damage the learning process. Inhibition in fulfilling the need of curiosity, makes the women frustrated and irritated leading to mood disorders. ${ }^{7}$

\footnotetext{
${ }^{6}$ Albert Bandura, "Social cognitive theory," in Annals of child development: Six theories of child development, ed. R. Vasta (Greenwich, CT: JAI Press, 1986)

${ }^{7}$ Henry Murray, Explorations in personality: (New York, Oxford University Press, 1938):66
} 
According to Powell, ${ }^{8}$ this thinking of being evaluated by others creates social apprehension in them. Domestic violence towards the women also plays an important role to their nervousness. Both studies concluded that, although, economic autonomy as well as temporary absence from home are factors which may help the working women to cope effectively. Despite that, once acquired working women's mental health is hampered because of the tendency to avoid distressful situation, which is inevitable in the working situation. Moreover, women who do not work, spend a lot of time with their family members. Hence, their emotional bond is much stronger which helps to remain mentally fit and healthy, as human bonding helps an individual remain healthy and stable mentally.

In contrast Abraham, ${ }^{9}$ agreed together with the earlier mentioned some studies reported that employed women possess more sound psychological and mental health status than housewives. It is being concluded that those women who are working and considered that their professional role is a source of self-fulfillment scored high on satisfaction with life scale. They further added that employed mothers are psychologically healthier and sound than those mothers who are not employed.

\section{Literature Review}

Wood Smith ${ }^{10}$ revealed that in most areas of Pakistan's society, people live in joint family system compelling strictly follow the norms. The joint family system in Pakistan and India strongly influence the habitants. There are two out of ten families who avoid sending their female children to schools due to the adherence of old conservative customs and traditions. Since they perceive that why a woman should get education as education is only necessary for work purpose and there is no use of it in their daily lives. The nonworking-women are having lesser liberty, facility of mobility and access to civilised quality of life as they are compelled to live within the four walls. In a recent study of Women's mental health Thara and Patel found that over 13 million Pakistani populations, the proportion of female is 52\%.The literacy rate of females in Pakistan is significantly low i.e. about $1.8 \%$. It is due to lack of attention by the successive Governments. A very low percentage of total Gross Domestic Product (GDP) is allocated for education in Pakistan, which is alarming. Furthermore, access to education for females is another major issue in Pakistan.

However, education in urban areas is bit easier as compared to rural areas of Pakistan. In the rural areas schools are far away from home and have no proper transport facility and those, which are there, have fewer resources to educate their children.

Although, currently working-women are not as much bounded as they were in the past and they are enjoying most of their liberties and rights as provided by constitution of

\footnotetext{
${ }^{8}$ Enoch Powell, The relationship between age and deep level study habits in a vocational nursing program: (USA, Sam Houston State University, Department of Curriculum and Instruction, 2011):48

${ }^{9}$ Abraham, Isolation as a form of marital violence: Journal of Social Distress and the Homeless, (2011):225

${ }^{10}$ Wood Smith, "Body image perception of active outdoorswomen: Toward a new definition of physical attractiveness," in Athletic participation and its effect on the eating behaviors of college women: Social Distress and the Homeless, Unpublished (USA, Florida State University College of Education, 2007) :222
} 
Pakistan and International Charter of Fundamental Human Rights. Especially in developed areas of Pakistan e.g. Karachi and Islamabad, girls are getting educational privileges equally in the schools, colleges and universities side by side with boys. As stated by Barker, ${ }^{11}$; Thara and Patel ${ }^{12}$ the differences between working and non-workingwomen are diminishing by increasing awareness through media. Globalization is exerting a positive change in the life of women living in the villages and cities. However, it is also observed that females are still the target of victimization at various places in urban areas as well. Mahjabeen ${ }^{13}$ found out that those females, who work and living in the cities still facing difficulties of getting admission in schools, institutes and getting jobs.

On the other hand, People permanently living in urban areas respect and value their women to be a part of earning member of family and their status is comparatively improved in comparison to the past. Naeem Aslam ${ }^{14}$ argued that such positive attitude towards working women shelter them from feeling of rejection and being failure or mental illness. They feel confident and honorable.

Unlike, the Western society, Pakistan's society has a male dominant culture, where a male is responsible for financial and domestic matters. Males are perceived as the responsible and powerful person. It is further observed that people in Pakistan and India feel emotionally upset, on the birth of a daughter whereas, on the birth of a son is taken as a source of celebration.

It was also observed that initially, people avoid to get marry with a girl who is working but now they look for a working spouse as she could serve as a supporting hand and nurture her children in a better way than a traditional housewife. Now, people acknowledge the working women's contribution to combat the financial needs of their families that is assumed as the guarantee of prosperous future of their families.

The conventional idea of women staying at home and men going out to earn livelihood still prevails in some rural areas of Pakistan.

These variations seem to have a stronger impact on lower middle class families than working and upper class families. Alison and Paquin ${ }^{15}$ defined the difference of socio economic status and the level of disadvantages in the housewives' status. It was spelled that females who belong to upper and middle socioeconomic strata of Pakistan are keen to social, political and economic benefits. Meanwhile, some females from the upper and

\footnotetext{
${ }^{11}$ Barker, D. Antecedents of stressful experiences: Depressive symptoms, self-esteem, gender, and coping. International Journal of Stress Management, 14, no.4(2007):340

${ }^{12}$ Thara, R. and Vikram Patel, (2006) Women's mental health: A public health concern. Regional Health Forum WHO South-East Asia Region,

${ }^{13}$ Mahjabeen Agha, (2004) Women Education in Pakistan: Still a Great Phenomenon, Accessed August 02 2013

${ }^{14}$ Naeem Aslam, Psychological disorder and resilience in earth quake affected individuals: Assessment in Africa Unpublished dissertation, (Pakistan: Islamabad, Quaid-e-Azam University, National Institute of Psychology, 2007): 147

${ }^{15}$ Alison Michaud \& Sophie Paquin, Women's safety: The security of urban women: practice, research, and partnerships. Injury Prevention: 8, no. 4 (2002): 15-16
} 
lower classes also enjoy social, political and economic status. Most of the females who belong to the elite families have different types of apprehensions, such as they have no burden of households responsibilities due to servants and have no need to do a job for financial gains, rather they have worries regarding dependency on their husbands and they feel insecure of being neglected by the husband due to a second woman. When a female is not doing a paid job or contributing financially, she is at the stake of her husband that how he treats her, as she fully dependents on him. The dominant males over the dependent females feel themselves as well-fed, well-dressed and well ornamented slaves of their husband who use them for full filling their urges. Their husbands treat them in in-human ways but they have no other option except living with them.

In a study Fatima ${ }^{16}$ found that in the last decade, the professional literature has addressed employed and household women on a continuum. A working- woman generally has a higher level of formal education, a higher level of income, and more social relations than the counterpart. A working-woman also typically lives in a resource-rich environment and has greater access to prenatal care and public transportation. The reduced geographical distance between family and friends in the working-women results in less social isolation as compared to the nonworking-women. These characteristics may have a negative impact on the nonworking-women who may be less able to read and understand patient education materials, afford or access routine healthcare and attend regular appointments. These factors may negatively influence the woman's attempt to deal with unfamiliar symptoms and life challenges.

Nevertheless, different studies including $\mathrm{Bala}^{17}$ argued oppositely that residents of nonworking-women often have lower educational levels, lower socioeconomic levels, more insecurity, and have greater travel distances to access healthcare than their (working-women) counterparts.

Moses ${ }^{18}$ studied on Gender difference that in Asian society for example India, Pakistan, Sri Lanka and Malaysia the most of the dominating positions are in males' hands and females are just passive part of the society and mostly females married through an arranged marriage system within the families and they have no choice to give their inputs in their parents or family's (Biraderis) decision. No female particularly in rural area can run her business without the "saya" (shelter) of a male. Moreover in the poorer areas daughters are sold for monetary purposes to their future husbands who sell them after divorce. A female who accepts this is given as a prized object. This practice is also happening in Indian Occupied Kashmir and the beautiful girls are sold to brother houses.

The objective of the study is to investigate the difference of depression among working and non-working, living in Karachi, Pakistan. Since previous researchers found that working women are more vulnerable to get sexually harassed at their work place. They

${ }^{16}$ Fatima Maqsood, A Study of Job Satisfaction among Nurses, Unpublished Thesis: (Pakistan: University of Punjab, Department of Sociology, 2007) :12

${ }^{17}$ Bala Hanuman, (2010). The Study of Determinants and Correlation of Job Satisfaction and Living Satisfaction: The Labour and Economy, 23, no.1, (2010): 102, the Korean Labour and Economy Society. ${ }^{18}$ Moses, C. Ossai, Age and gender difference in study habits: A framework for proactive counselling against low academic achievement. Journal of Educational and Social Research, 2, (2012):69 
get more stress as compare to nonworking females, who stay at the homes. Considering the past researches, it was hypothesized that:

There will be a significant difference between working-women and non-working women on the variable of depression.

\section{Method \\ Participants}

The sample for the current study was taken from Karachi city. Since, Karachi is considered as a capital of province named Sindh. Karachi is a multi-populated city of Pakistan and the people who belong from different areas around Pakistan come to earn a living for their families here. Since, ample and multi cultured people live in the city the data of this city may has a significant value to generalize as Pakistan's sample. An easily available of targeted women such as teaching, non-teaching staff, women Bankers, paramedical staff and house wives were chosen from various commercial organizations including, Jhangeer Siddiqui Bank Ltd, Cresguard Systems (Pvt) Ltd, Fulcrum Pvt Ltd as well as Jinnah Hospital. A total sample of 250 women was taken for the study through purposive sampling technique. It was further divided in to two groups of 125 nonworking women and 125 working-women. The age range was between 28 to 45 years $(\mathrm{M}=34.12 ; \mathrm{SD}=4.12)$. The sample's minimum level of education was 14years. The women's socioeconomic status (SES) was evaluated by family incomes.

\section{Measures}

\section{a) Demographic Form}

In order to explain the implications of the study, researchers gather the personal information of the participant. In the current study, the information was taken on the variables of marital status, education, age, income, occupation and family structure. To collect the demographic information of the subjects (women), a demographic form was written and given to the women.

\section{b) Depression Anxiety Stress Self-esteem (DASS Scale (1995)}

Lovibond and Lovibond (1995) had created the scale DASS. The scale was designed to measure the three dimensional self-report emotional illness; state of depression, anxiety and stress. Every one of three DASS does 14 items; those are further divided into 2-5 subscales with the similar aspect. DASS assesses dysphasia, hopelessness, and emptiness of life, lack of interest, self-deprecation and inertia. It also helps to determine difficulty level to relax, nervous arousal, and being easily agitated and impatient. The participants are asked to reply at 4-point Likert scale rating the limit to which they have gone through the state over the past one week. The three of scores; those are Depression, Anxiety and Stress are computed by adding up, respectively. DASS Urdu version was administered, translated, since Urdu is considered as widely spoken language around Pakistan. "DASS, Alpha coefficient for overall factor (total scores) is 0.71 for depression, 0.86 for anxiety and 0.88 for stress". 
"Reliability of DASS is considered as high that is 0.71 for depression, 0.79 for anxiety and 0.81 for stress" (Lovinbon \& Lovinbond, 1995).

\section{Procedure}

Researcher arranged the scales those were supposed to use in the study. The scales DASS was freely available on internet, hereby, permission was already granted.

In order to collect the data of working women, first of all, multiple commercial organizations were approached. The organizational heads were explained the purpose of the research and a 'Request of permission to collect the data, was also be asked. The telephonic and e-mail permissions were taken. The letters of consent were given to the non-working females in physical presence. Secondly, in the view of obtained official permission, the samples were approached comfortably and then individually briefed the reason of the research. They were told the ethics of research participation as a volunteer subject. The women were informed that they could withdraw their participation at any time. The confidentiality of the findings was also being rest assured. Thirdly, they were requested to sign the consent form to participate in the research. A demographic form containing information about age, marital status, education, socioeconomic status, income, family structure, occupation, profession was asked to fill. Each participant was interviewed separately (one participant at a time). All of the participant's marital status was constant; married. Finally, DASS was administered on women to measure their subjective depression.

The women, who were taken as a control group in the study, were approached at their homes and universities (students). They had no background history of paid work. The same procedure was adopted to gather the information from non-working women.

\section{Results}

The t-test indicates that non-working-women showed higher mean scores on the variable of depression than the mean scores of non-working women.

\section{Table 1}

\begin{tabular}{|l|c|c|c|}
\hline Groups & & & \\
\hline Nonworking women & 125 & 34.46 & 5.138 \\
\hline Working women & 125 & 34.47 & 5.136 \\
\hline
\end{tabular}


Table 2

\begin{tabular}{|c|c|c|c|c|c|c|}
\hline \multirow{2}{*}{$\begin{array}{r}\text { Age } \\
28\end{array}$} & \multicolumn{2}{|c|}{$\begin{array}{c}\text { None-Working- } \\
\text { Women }\end{array}$} & \multicolumn{2}{|c|}{ Working-Women } & \multicolumn{2}{|c|}{ Total } \\
\hline & 5 & 4 & 5 & 4 & 10 & 4 \\
\hline 29 & 4 & 3 & 4 & 3 & 8 & 3 \\
\hline 30 & 16 & 13 & 16 & 13 & 32 & 13 \\
\hline 31 & 14 & 11 & 14 & 11 & 28 & 12 \\
\hline 32 & 6 & 5 & 6 & 6 & 12 & 5 \\
\hline 33 & 10 & 8 & 9 & 7 & 19 & 8 \\
\hline 34 & 13 & 11 & 13 & 10 & 26 & 10 \\
\hline 35 & 13 & 11 & 14 & 11 & 27 & 9 \\
\hline 36 & 9 & 7 & 9 & 7 & 18 & 8 \\
\hline 37 & 8 & 7 & 8 & 6 & 16 & 6 \\
\hline 38 & 2 & 2 & 2 & 2 & 4 & 2 \\
\hline 39 & 11 & 9 & 11 & 9 & 22 & 9 \\
\hline 40 & 5 & 4 & 5 & 4 & 10 & 4 \\
\hline 43 & 4 & 3 & 4 & 3 & 8 & 3 \\
\hline 44 & 4 & 3 & 4 & 3 & 8 & 3 \\
\hline 45 & 1 & 1 & 1 & 1 & 2 & 1 \\
\hline Total & 125 & $100.00 \%$ & 125 & $100.00 \%$ & 250 & $100.00 \%$ \\
\hline
\end{tabular}

Table 3

\begin{tabular}{|l|c|c|c|c|c|c|}
\hline Variable & $\boldsymbol{N}$ & $\boldsymbol{M}$ & $\boldsymbol{S D}$ & $\boldsymbol{S E M}$ & $\boldsymbol{T}$ & Sig \\
\hline Non-Working & 125 & 14.28 & 13.95 & 0.35 & & \\
\hline Working & 125 & 10.26 & 5.67 & 0.507 & & \\
\hline
\end{tabular}

There is statistically difference in mean scores of Working and Non-Working women on the variables of Depression, where working women scored lower than non-working women.

The p-value is maximum probability occurring in true value is probability-value is less than level of significance it means significant relation between the variables. 
Table 4

(This table shows frequencies and percentages of working-women according their profession.)

\begin{tabular}{|l|c|c|c|c|}
\hline \multicolumn{1}{|c|}{ Designation } & Frequency & Percent & Valid Percent & $\begin{array}{c}\text { Cumulative } \\
\text { Percent }\end{array}$ \\
\hline Paramedics & 12 & 9.6 & 9.6 & 9.6 \\
\hline Advocate & 13 & 10.4 & 10.4 & 20.0 \\
\hline ASM Pahrma & 9 & 7.2 & 7.2 & 27.2 \\
\hline Banker & 9 & 7.2 & 7.2 & 34.4 \\
\hline Doctor & 23 & 18.4 & 18.4 & 52.8 \\
\hline Field Work & 5 & 4.0 & 4.0 & 56.8 \\
\hline $\begin{array}{l}\text { Health } \\
\text { Supervisor }\end{array}$ & 6 & 4.8 & 4.8 & 61.6 \\
\hline MM & 9 & 7.2 & 7.2 & 68.8 \\
\hline Officer & 6 & 4.8 & 4.8 & 73.6 \\
\hline Social Worker & 9 & 7.2 & 7.2 & 80.8 \\
\hline Teacher & 24 & 19.2 & 19.2 & 100.0 \\
\hline Total & 125 & 100 & 100 & -- \\
\hline
\end{tabular}

\section{Discussion}

The employed women scored lower on the scales of Depression compared to the nonworking-women. Although, the education level of the both groups of women was taken equal, employed females were seemed to be more aware than the counterpart. Since, employed women have better and vast exposure of outer world as well as household experiences; they learn and deal the stressors better than the non-working women.

The similar findings revealed as the current study, in the study of Bastable, (2008) that those women who have opportunity to go outside to work and support their families financially and utilize their helps, inner potential, skills and knowledge.

The results depict the higher level of depression; one of the reasons may take in to account, the findings of World Health Organization's report $(2006,2004)$ that females, competent enough, who stay at home, have also the feeling that their talent was being gone in vein. These feelings create frustration to them, such female have the perception 
that no one values them adequately for their participation in household works at their homes. $^{19}$

According to the results of the demographic sheet, the working women's divorced percentage is lesser than the non-working women. It is also highlighted in the earlier chapter that the culture of Pakistan is based on the joint family system. The family members are bound to follow the cultural norms and decisions of the elders of the families. The marriages and divorces are done on the wish of the elders and the parents, rather than the girls and boys. However, working ladies have slightly higher the rights to practice the liberty in this regard. They get better chances to take decision to who to marry or weather get separated or live together. Further, a working lady contributes to gain the finance for the family, so that the acceptance in the family may be higher than a non-working lady. The higher percentage of divorce in nonworking ladies may be considered as an indicator of higher scores of depression than the working-ladies. Since the previous studies showed that rejections, suppressions and frustration cause the depression. Nevertheless, the scores difference is not as much significant that it could be taken as a sole reason; it may count as the one of the supporting factors to cause depression in non-working-women in Pakistan. ${ }^{20}$

\section{The Age and Depression}

The results of table no. 4 reflect the frequencies and percentages distribution of nonworking and working-women regarding their age that is ranged between 28 years to 45years. It is medically proved that females have a menopause period. Generally, this period starts from the age of forty five in Pakistan. The scores of the present study may be linked to the menopause in causing nonworking women's higher rate of depression. Since, the house-wives feel worthless after completing their families as they follow the family planning. The non-working-women, unlike the working women, have no other activities of socialization in Pakistan. Before the menopause period, women start feeling alone and hopeless because of social withdrawal that leads to depression. This issue may play as an indicator of the depression in non-working-women in Pakistan.

\section{Profession and the Mental Health of Women in Pakistan}

The figures on the table no.4 show the frequencies and the percentages of the workingwomen and non-working-women regarding their profession. Doctor's and teacher's profession is considered as a prestigious career in Pakistan. Families, generally allow their females to opt these professions, so the percentage of medical practitioners and teachers is the highest. The social support leads to better mental health and confidence in the working women, leading to a satisfactory self-esteem. The professional women's need to be respected gets gratification, in this way (Miller, 2002; Maslow, 1954; Alferd,

\footnotetext{
${ }^{19}$ Moses, C. Ossai, Age and gender difference in study habits: A framework for proactive counseling against low academic achievement. Journal of Educational and Social Research, 2, (2012): 67-73

${ }^{20}$ Hanam, B, (2010). The Study of Determinants and Correlation of Job Satisfaction and Living Satisfaction: The Labour and Economy, 23 (1), 93-126, the Korean Labour and Economy Society. Retrieved from http://www.highbeam.com/doc/iGi-306182802.html [Accessed on August 21 2016]
} 
1927). ${ }^{21}$ The second highest percentage also belongs to the medical field; those work as paramedics are taken as qualified and respectable than other professions.

\section{Conclusion}

According to the results of this study, it may be concluded that employment status considered as a positive factor of the working women's mental health. Further, lack of awareness of women rights, lack of education and the paucity of resources affect the women's mental health negatively.

\section{Recommendations}

In the view of the above discussion, it may be suggested that the working conditions especially for women in Pakistan should be improved. The women of Pakistan may play a substantial role to bring the economic revolution, since; they are in majority i.e. 52\% of whole population.

This study may be very beneficial for not only having a healthy organizational culture but also for societies and household issues.

\section{References}

Aaron T. Beck, A. John Rush, Brian F. Shaw and Gary Emery, Cognitive Therapy of Depression: (New York: The Guilford Press, 1979) 11.

Abraham Maslow, Motivation and personality: (New York, NY: Harper 1954), 236.

Abraham, Isolation as a form of marital violence: Journal of Social Distress and the Homeless, (2011), 221-226.

Albert Bandura, "Social cognitive theory," in Annals of child development: Six theories of child development, ed. R. Vasta (Greenwich, CT: JAI Press, 1986), 1-60.

Albert Bandura, Self-efficacy: Toward A Unifying Theory of Behavioral Change, Psychological Review: 84, no. 2 (1977): 191-215

Alfred Adler, Heinz L. Ansbacher and Rowena R. Ansbacher:Superiority and Social Interest: A Collection of Later Writings (New York, Norton, 1979).

Alfred Adler, Heinz L. Ansbacher and Rowena R. Ansbacher: The Individual Psychology of Alfred Adler (New York: Harper Torchbooks, 1964).

Alison Michaud \& Sophie Paquin, Women's safety: The security of urban women: practice, research, and partnerships. Injury Prevention: 8, no. 4 (2002): 15-16

${ }^{21}$ Maslow, A. Motivation and personality. (New York, NY: Harper, 1954), p. 236. 
Bala Hanuman, (2010). The Study of Determinants and Correlation of Job Satisfaction and Living Satisfaction: The Labour and Economy, 23, no.1, (2010) 93-126, the Korean Labour and Economy Society. http://www.highbeam.com/doc/iGi-306182802.html August 212013

Barker, D. Antecedents of stressful experiences: Depressive symptoms, self-esteem, gender, and coping. International Journal of Stress Management, 14, no.4(2007): 333349.

Boston University School of public Health (2013): The theory of planned behavior, http://sph.bu.edu/otlt/MPH-Modules/SB/SB721-Models/SB721-Models3.html

Carl Rogers, Some observations on the organization of personality, American Psychologist: 2 (1947):358-368

Coleman Jensen, Working for Peanuts: Nonstandard Work and Food Insecurity A cross Household Structure, Journal of Family and Economic Issues: 32, no.1 (2010): 84-97.

De Silva, The association between economic and social factors and mental health (2010): www.knoweldge.sagepub.com/view/researchdesign/n 145.xml.D01:10

Enoch Powell, The relationship between age and deep level study habits in a vocational nursing program: (USA, Sam Houston State University, Department of Curriculum and Instruction, 2011),

Erik H. Erikson, Childhood and Society: (New York: Norton, 1950).

Fareda Zeab, Feeling of security-insecurity in working-women \& non-working-women in Pakistan, Post Graduate Unpublished thesis: (UK: Bucks New University, 2011).

Farida Shaheed and Khawar Mumtaz, Women's Economic Participation in Pakistan. Status Report for UNICEF Pakistan (2010): September 3 2013, http://eprints.hec.gov.pk/442/1/151.html.htm

Fatima Maqsood, A Study of Job Satisfaction among Nurses, Unpublished Thesis: (Pakistan: University of Punjab, Department of Sociology, 2007)

Hamza Alavi, Pakistani women in a changing society (2010):Accessed 24 August 2013: http://ourworld.compuserve.com/homepages/sangat/pakwomen.htm

Henry Murray, Explorations in personality: (New York, Oxford University Press, 1938)

Jeanette, C Esomonu, The relationship of employment to self-perception and well-being in women: A cognitive analysis, Journal of Teacher Education and Teaching, 8 no.1, (2010): 360-366.

Jejeebhoy, Shireen, J., Zeba A. Sathar, Women's Autonomy in India and Pakistan: the influence of Religion and Region, Population and Development Review, 27, no.4 (2011): 687-712. 
Mahjabeen Agha, (2004) Women Education in Pakistan: Still a Great Phenomenon, Accessed August 022013 http://www.aljazeerah. info/ Opinion editorials/ opinions/o/Women Education in Pakistan Still a Great Phenomenon by Mahjabeen. Htm

Moses, C. Ossai, Age and gender difference in study habits: A framework for proactive counseling against low academic achievement. Journal of Educational and Social Research, 2, (2012): 67-73.

Moses, C. Ossai, Perspectives on working women: Bureau of Labour Satistic. Mediterranean Journal of Social Sciences, 2, (2011): 23-28.

Munchinsky, Employee Absenteeism: A Review of the Literature. Journal of Vocational Behavior, 10, (2007): 326-340.

Naeem Aslam,Psychological disorder and resilience in earth quake affected individuals: Assessment in Africa Unpublished dissertation, (Pakistan: Islamabad, Quaid-e-Azam University, National Institute of Psychology, 2007): 139-151.

National Center for Chronic Disease Prevention and Health Promotion. (2010). the burden of chronic diseases, their risk factors. National, State Perspectives, 2004. Atlanta, GA: USDHHS.

S.H. Lovibond and P.F. Lovibond, Manual for the Depression Anxiety Stress Scales: (Sydney, Psychology Foundation, 2005): 210-213

Sigmund Freud, Analysis of phobia of a five year old boy: (The Pelican Freud Library 1977), Case Histories 8, no.1, 169-306

Sigmund Freud, Heredity and the etiology of the neuroses: In Standard(1896).

Thara, R. and Vikram Patel, (2006) Women's mental health: A public health concern. Regional Health Forum WHO South-East Asia Region, Accessed Sep 17 2013 http://209.61.208.233/en/Section1243/Section1310/Section1343/Section13 44/ Section 1353_5282.htm

Uzma Ali, Ayesha Khan and Seema Munaf, Attitudes toward Women in Managerial Position in Pakistan: International Journal of Information and Education Technology, 3, no.3 (2013): 373-377.

Wood Smith, "Body image perception of active outdoorswomen: Toward a new definition of physical attractiveness," in Athletic participation and its effect on the eating behaviors of college women: Social Distress and the Homeless, Unpublished (USA, Florida State University College of Education, 2007) 221-226.

World Health Organization, (2006) Women's Mental Health: A Public Health Concern. Accessed July 4, 2013, http://www.searo.who.int/EN/Section1243/Section1310/Section1343/Section1344/Sectio n1353_5282.htm 